\title{
CHEMICAL REACTION KINETICS OF 1,5-BIS (3'-ETHOXY-4'-HYDROXYPHENYL)-1,4- PENTADIENT-3-ONE SYNTHESIS WITH FOOD GRADE RAW MATERIAL
}

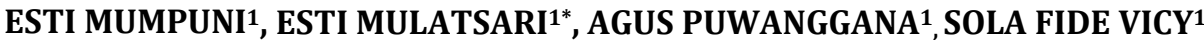 \\ 1Faculty of Pharmacy, Universitas Pancasila, Jakarta, Indonesia \\ *Email: esti.mulatsari@univpancasila.ac.id
}

Received: 09 Sep 2020, Revised and Accepted: 09 Oct 2020

\begin{abstract}
Objective: This research aims to develop the 1,5-bis (3'-ethoxy-4'-hydroxyphenyl)-1,4-pentadient-3-one (EHP) synthesis method from ethyl vanilin with food-grade quality and determines the order reaction and formation reaction rate constant of EHP.

Methods: Synthesis of the EHP was carried out by reflux the starting material, ethyl vanillin (food grade) of various weights, acetone and hydrochloric acid as catalysts. The reflux results are then condensed for two days at cold temperatures. Determination of the reaction order and reaction rate constants are carried out by the graph method based on the reduction in the concentration of ethyl vanilin, which reacts with acetone each time unit.

Results: The results showed the formation of EHP, which was synthesized by starting material of ethyl vanilin food grade 4 and 8 grams following pseudo-first-order reaction kinetics with reaction rate constants respectively 0,0116/minute and 0,005/minute. The formation of EHP, which was synthesized by starting material ethyl vanilin food grade 16 and 18 grams following zero-order reaction kinetics with reaction rate constants respectively $0,1451 \mathrm{mg} / \mathrm{ml}$ minute and $0,248 \mathrm{mg} / \mathrm{ml}$ minute.
\end{abstract}

Conclusion: The synthesis of EHP from ethyl vanilin with food-grade quality has been success develop. The order reaction kinetics are different in the different mass of ethyl vanillin used.

Keywords: EHP, Chemical reaction kinetics, Food grade ethyl vanillin

(C) 2021 The Authors. Published by Innovare Academic Sciences PvtLtd. This is an open access article under the CCBYlicense (http://creativecommons.org/licenses/by/4.0/) DOI: http://dx.doi.org/10.22159/ijap.2021.v13s2.13 Journal homepage: https://innovareacademics.in/journals/index.php/ijap

\section{INTRODUCTION}

Indonesia is rich in biodiversity, which is considered as a medicinal ingredient. One of the natural ingredient that has been developed and researched is Curcumin. Curcumin is a yellow phenolic compound contained in Curcuma longa (turmeric) and several other Curcuma species, which has antioxidant activity, hepatoprotector, inhibitor of several enzymes, anticancer, anti-inflammatory, immunomodulatory and antimicrobial [1]. Due to these various activities, various modifications have been made to the structure of curcumin to increase its stability, potency, selectivity and bioavailability [1]. By modifying the chemical structure of curcumin, Sardjiman et. al has succeeded in obtaining and synthesizing three curcumin derivatives, named pentagamavunon, hexagamavunon, and gamavuton.

Gamavuton is one of the curcumin analogue that is synthesized at cold temperatures using aromatic aldehyde and acetone as well as hydrochloric acid catalyst without using solvents [2]. The chemical structure of Gamavuton can be modified by changing the methoxy group to ethoxy to produce a new compound named 1,5-bis (3'ethoxy-4'-hydroxyphenyl)-1,4-pentadien-3-one (EHP). EHP has better biological activity than curcumin, pentagamavuton, hexagamavuton, and gamavuton [1].

EHP has antioxidant and antibacterial activity. EHP is stronger in warding off free radicals so that the antioxidant activity of EHP is better than curcumin and gamavuton [3]. The antibacterial activity test showed that antibacterial potential of EHP is better than amoxicillin and cefadroxyl in killing gram-positive bacteria (Staphylococcus aureus, Staphylococcus epidermidis) and gramnegative bacteria (Eschericia coli, Salmonella thypi) [4]. EHP was known has anti-inflammatory activity [5].

EHP has a lot of benefits making this compound a great potential to be produced on an industrial scale. This is reinforced by the cheapness of food-grade ethyl vanillin as starting materials. So that it is hoped that new domestic-produced drugs will be available which is effective, safe, affordable to the public and able to compete in the market. To develop the synthesis EHP into an industrial scale, it is necessary to develop the optimum conditions for the synthesis
EHP using food-grade ethyl vanillin as starting materials that are effective and efficient; and studying the chemical reaction kinetics about formation reaction of EHP by determining the reaction order and reaction rate constants.

Chemical kinetics is a branch of chemistry that studies the velocity of chemical reactions [6]. Reaction kinetics can be studied by varying one of the factors that affect the rate of the reaction (for example, the concentration of reactants) and controlling for other factors (for example, temperature and catalyst concentration) [7]. Information on the reaction rate constants and the reaction order of reagents can be used to design factory equipment and reactors in the production process [8].

The data needed to synthesize EHP in an industrial scale include reaction order and reaction rate constants. Reaction order cannot be determined by looking at the equation of a reaction but must go through an experiment [9]. One of them is by varying the weight of one of the reactants, like food-grade ethyl vanillin and controlling other factors such as temperature and catalyst concentration. This is because the chemical reaction mechanism consists of several steps and the reaction rate is often determined by the speed of the reaction steps [10]

Reflux is a method in chemistry to synthesize a compound, both organic and inorganic [11]. Generally used to synthesize compounds whose initial ingredients are volatile. In this condition, when heating is usually the initial material is volatile before the reaction runs to completion. The principle of the reflux method is that volatile materials will evaporate at high temperatures, but will be cooled by a condenser so that the material that was in the form of vapor will condense on the condenser and fall back into the reaction vessel so that the solvent or reactants will remain during the reaction [12].

\section{MATERIALS AND METHODS}

\section{Materials}

The materials that were used in determine the reaction order and formation reaction rate constant of EHP were food-grade ethyl 
vanillin (Sigma Aldrick), acetone (Merck), and concentred hydrochloric acid 37\% (Merck).

\section{Instrumentation}

The apparatus that was used in determine the reaction order and formation reaction rate constant of EHP were Beaker glass (Pyrex), test tube (Pyrex), $100 \mathrm{ml}$ measuring cylinder (Pyrex), rough scales (Pyrex), boiling stone, three-neck gourds, thermometer, condensor, heat mantle (SEOH), 1 and $2 \mathrm{ml}$ volumetric pipette (Pyrex), $10 \mathrm{ml}$ volumetric flask (Pyrex), rubber bulb, spectrophotometer ultraviolet-visible (Shimadzu UV 1900), and refrigerator.

\section{Preparation of standard food-grade ethyl vanillin}

Weighed carefully approximately $20 \mathrm{mg}$ of food-grade ethyl vanillin, then dissolved in $10.0 \mathrm{ml}$ acetone. The solution was pipette $2.0 \mathrm{ml}$ then added acetone up to $10,0 \mathrm{ml}$ and homogenized.

\section{Monitoring the concentration of ethyl vanillin per unit time}

The ethyl vanillin powder was weighed 4 grams, then added with 50 $\mathrm{ml}$ acetone and stirred until it was homogeneous in a three-neck flask. Added concentred hydrochloric acid $1 \mathrm{ml}$, and boiling stone. The thermometer is attached to the hole on one side of the threeneck flask. The other hole on the other side is blocked with a rubber stopper. The condenser is installed and set over the three-neck flask and the heat mantle underneath the flask. The heat mantle is turned on and it is ensured that water always flows through the condenser. The temperature is maintained at $70^{\circ} \mathrm{C}$. After the temperature reaches $70{ }^{\circ} \mathrm{C}$, pipette $1.0 \mathrm{ml}$ of the reactant mixture then add acetone to $10.0 \mathrm{ml}$. Pipette $1.0 \mathrm{ml}$ of the solution again, then add acetone to $10.0 \mathrm{ml}$. The ethyl vanillin in the solution was measured for absorbance at a wavelength $333.5 \mathrm{~nm}$. Measurement of ethyl vanillin absorbance for reactants was also carried out at 10 to 90 min. After the reflux process is complete, the reflux compound is transferred to the erlenmeyer, then closed its mouth and cooled for $2 \mathrm{~d}$ in a refrigerator. The same was done for the variation of ethyl vanillin weights 8,16 , and 32 grams.

\section{Statistical analysis}

Statistical evaluation of variation concentration of ethyl vanillin per unit time carried out using the SPSS with One-sample t-test. Data were expressed as the significance value (Sig). Sig 0,05 was considered the concentration of ethyl vanilin statistically significant for [13].

\section{RESULTS}

Determination of the reaction order and formation reaction rate constant of EHP

The reaction kinetics formation of 1,5-bis (3'-ethoxy-4'hydroxyphenyl)-1,4-pentadien-3-one (EHP) was determined based on the reduction concentration of ethyl vanillin as a reactant each time unit. The reduction concentration of ethyl vanillin was only caused by the cross-aldol condensation reaction between ethyl vanillin and enolate from acetone, which was accelerated by the acid catalyst to produce a candidate compound for the EHP product [2]. Monitoring the reduction of the concentration of ethyl vanillin for synthesis EHP with variations in the weight of the starting material of ethyl vanillin food grade 4, 8, 16, and 32 grams resulted in data the concentration of ethyl vanillin which decreased each time unit. Determination of concentration was carried out by directly comparing the ethyl vanillin absorbance sampled each unit time with ethyl vanillin absorbance as a standard whose concentration was known. Ethyl vanillin concentration data per unit time are shown in table 1.

Table 1: Ethyl vanillin concentration data per unit time

\begin{tabular}{|c|c|c|c|c|c|}
\hline \multicolumn{2}{|c|}{ Food grade ethyl vanillin raw material (grams) } & 4 & 8 & 16 & 32 \\
\hline Concentration of ethyl vanillin $(\mathrm{mg} / \mathrm{ml})$ per & 0 & 38.4635 & 40.5462 & 37.9874 & 42.5100 \\
\hline unit time (minutes) & 10 & 36.9000 & 37.8035 & 37.2733 & 41.5957 \\
\hline & 20 & 33.7840 & 36.7486 & 36.2455 & 38.1984 \\
\hline & 30 & 29.5860 & 34.2790 & 34.8010 & 36.1102 \\
\hline & 40 & 24.5171 & 32.9184 & 33.7137 & 34.1032 \\
\hline & 50 & 23.4838 & 32.1178 & 32.9563 & 30.3704 \\
\hline & 60 & 20.9304 & 30.2893 & 30.2514 & 28.8719 \\
\hline & 70 & 18.6042 & 28.1687 & 29.0018 & 25.6694 \\
\hline & 80 & 15.9750 & 27.6006 & 26.7459 & 23.9923 \\
\hline & 90 & 13.7084 & 25.2312 & 25.1987 & 20.5301 \\
\hline
\end{tabular}

To determine whether there is a significant effect effect of the cross aldol condensation reaction on the reduction in the concentration of ethyl vanillin at each time unit. It was analyzed statistically. Ethyl vanillin concentration data for each unit of time obtained were analyzed by one-sample t-test. Statistical test with One-sample t-test uses the $95 \%$ confidence level. Table 2 presents the calculated significance value of One-sample t-test on each variable and the results of hypothesis testing.

Table 2: The calculated significance value of one-sample t-test

\begin{tabular}{lll}
\hline Food grade ethyl vanillin (grams) & Calculated significance value & Result \\
\hline 4 & 0.001 & Significantly different \\
8 & 0.000 & Significantly different \\
16 & 0.002 & Significantly different \\
32 & 0.001 & Significantly different \\
\hline
\end{tabular}

Table 2 presents that the calculated significance value of the onesample t-test on each variable is less than 0.05 . This suggests that there is an effect between the cross aldol condensation reaction on the reduction the concentration of ethyl vanillin per unit time. In other words, the concentration of ethyl vanillin at each time unit was significantly different with the concentration of ethyl vanillin at $t=0$. Determination of the reaction order is done by graphing the relationship between time (minutes) vs changes in reactant concentration. The reaction order is based on the most linear graph which is indicated by the value of the correlation coefficient $\left(\mathrm{R}^{2}\right)$, which is the largest (close to 1) of the correlation curve between concentration; ln concentration; and 1 /concentration (y-axis) with time (x-axis). In this study, acetone and hydrochloric acid were made excess, so it can be analyzed that the reaction order is a pseudo-order model [10], where it is possible to have a pseudo-firstorder or pseudo-second-order reaction kinetics. The following is the analysis of the reaction kinetics of ethyl vanillin reduction which reacts with acetone to form a candidate compound for EHP products in each of the weight variations of food grade ethyl vanillin 4,8,16,32 grams. 

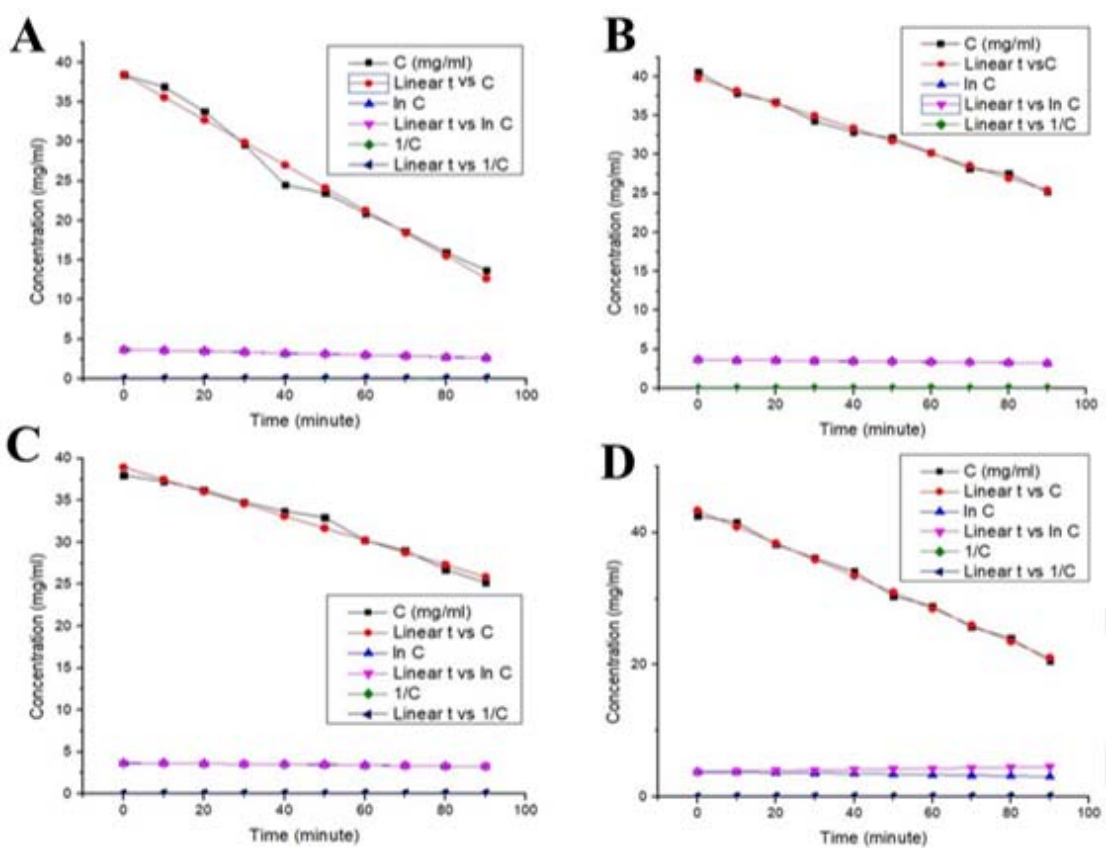

Fig. 1: Chemical reaction kinetics analysis curve of EHP synthesis weight variation of food grade ethyl vanillin: (A) 4 grams; (B) 8 grams; (C) 16 grams; (D) 32 grams

Table 3: Details of the rate constant the formation of EHP

\begin{tabular}{lll}
\hline Food grade ethyl vanilin (grams) & Correlation coefficient $\left(\mathbf{R}^{2}\right)$ & Gradient or reaction rate constants \\
\hline 4 & 0.9886 & $\mathrm{k}^{\prime}=0.0116 / \mathrm{minute}$ \\
8 & 0.9903 & $\mathrm{k}^{\prime}=0.0050 / \mathrm{minute}$ \\
16 & 0.9783 & $\mathrm{k}=0.1451 \mathrm{mg} / \mathrm{ml} \mathrm{minute}$ \\
32 & 0.9944 & $\mathrm{k}=0.2480 \mathrm{mg} / \mathrm{ml} \mathrm{minute}$ \\
\hline
\end{tabular}

\section{DISCUSSION}

In the synthesis of EHP with food-grade ethyl vanillin 4 grams as raw material, the $\mathrm{R}^{2}$ value for the zero-order kinetics graph model was 0.9841; whereas for the first and second-order kinetics graph model, respectively 0.9886; and 0.9505. Based on these data, the formation of EHP with food-grade ethyl vanillin 4 grams follows the pseudo-first-order reaction kinetics. In the synthesis of EHP with food-grade ethyl vanillin 8 grams as raw material, the $\mathrm{R}^{2}$ value for the zero kinetics graph model was 0.9899; whereas for the first and second-order kinetics graph model, respectively 0.9903 ; and 0.9805 . Based on these data, the formation of EHP with food-grade ethyl vanillin 8 grams follows the pseudo-first-order reaction kinetics. In the synthesis of EHP with food-grade ethyl vanillin 16 grams as raw material, the $\mathrm{R}^{2}$ value for the zero kinetics graph model 0.9783 ; whereas first and second-order kinetics graph model respectively 0.9620; and 0.9403. Based on these data, the formation of EHP with food-grade ethyl vanillin 16 grams follows the zero-order reaction kinetics. In the synthesis of EHP with food-grade ethyl vanillin 32 grams as raw material, the $\mathrm{R}^{2}$ value for the zero kinetics graph model was 0.9944; whereas the first and second-order kinetics graph model respectively 0.9793 ; and 0.9427 . Based on these data, the formation of EHP with food-grade ethyl vanillin 32 gram follows the zero-order reaction kinetics. The reaction kinetics following the zero order means that increase the concentration of ethyl vanillin the reaction has no effect on the reaction rate of EHP formation. If the reaction kinetics of reduction the concentration of ethyl vanillin follows the first order, it means that increase the ethyl vanillin concentration in the system will increase the reaction rate 2 times. Meanwhile, if the reaction kinetics of ethyl vanillin reduction follows second order, increasing the concentration of ethyl vanillin in the system will increase the reaction rate 4 times. The reaction order for the formation of EHP synthesized with food grade ethyl vanillin with weight variations of 4 and 8 grams follows the first-order reaction kinetics. This indicates that the reaction of EHP formation with food grade ethyl vanillin as starting materials with weight variations of 4 and 8 grams is faster than the reaction of EHP formation with food grade ethyl vanillin as starting material weight variations of 16 and 32 grams, which follow the zero-order reaction kinetics. The decrease in reaction rate in the formation of EHP with the starting material of ethyl vanillin food-grade variations of weight 16 and 32 grams indicates that an increase the amount of ethyl vanillin as the reactant, does not always provide an increase the rate of reduction in the ethyl vanillin concentration to forming EHP. That is due to an increasing amount of ethyl vanillin may causes the probability of collision between ethyl vanillin and acetone to decrease and the probability of collisions between ethyl vanillin molecules increases [14]. As a result, there is a decrease in the rate of reduction of ethyl vanillin to forming EHP. Determination of the reaction rate constants based on the gradient value (value b) on the graph of the reaction kinetics model, which is the most linear [10] or the value of the correlation coefficient $\left(\mathrm{R}^{2}\right)$ is the largest (close to 1). Table 3 details the gradient values on a linear graph of the relationship between time and changes in concentration.

\section{CONCLUSION}

The formation of 1,5-bis (3'-ethoxy-4'-hydroxyphenyl)-1,4pentadien-3-on (EHP) which was synthesized based on variations in the weight of the raw material of food grade 4 and 8 gram ethyl vanillin following pseudo-first-order reaction kinetics with rate constants respectively $0.0116 /$ minute and $0.005 /$ minute. Meanwhile the weight variation of the raw material of food-grade ethyl vanillin 16 and 32 gram following zero-order reaction kinetics with reaction rate constants respectively $0.1451 \mathrm{mg} / \mathrm{ml}$ minute and $0.248 \mathrm{mg} / \mathrm{ml}$ minute. The synthesis of EHP from ethyl vanilin with food grade quality has been success develop. The order reaction kinetics are different in the different mass of ethyl vanillin used. The synthesis is very potential to develop EHP as chemical drug material. 


\section{ACKNOWLEDGMENT}

The authors are grateful for a research grant from Ministry of Research, Technology and Higher Education of the Republic of Indonesia for funding the research.

\section{FUNDING}

Funding from the Ministry of Research, Technology and Higher Education of the Republic of Indonesia.

\section{AUTHORS CONTRIBUTIONS}

All the authors have contributed equally.

\section{CONFLICT OF INTERESTS}

There are no conflicts of interest.

\section{REFERENCES}

1. Mumpuni E, Purwanggana A, Mulatsari E. New antibacterial agent from curcumin derivative compounds. Bogor: PT. Idemedia Pustaka Utama; 2019.

2. Supardjan AM, Permatasari I. Synthesis of natural compounds 1,5-bis (4'-hydroxy-3'-methoxyphenyl)-1,4-pentadien-3-on. Trad Med Mag 2006;2:15-20.

3. Mumpuni E, Indriana P, Sulastri E, Rusnawan E. Synthesis and an antioxidant assay of 1,5-bis (3'-ethoxy-4'-hydroxyphenyl)-1,4pentadien-3-on (EHP). J Ilmu Kefarmasian Indones 2010;8:91-100.

4. Mumpuni E, Agus P, Mulatsari E. Antibacterial activity assay of 1,5-bis (3'-ethoxy-4'-hydroxyphenyl)-1,4-pentadien-3-on
(EHP) by in sillico and in vitro. Int J Pharm Pharm Sci 2018:10:70-6.

5. Mumpuni E, Lestari R, Arief N. Toxicity and anti-inflammatory of 1,5-bis (3'-ethoxy-4'-hydroxyphenyl)-1,4-pentadien-3-on (EHP). J Ilmu Kefarmasian Indones 2015;13:45-9.

6. Brady JE. General chemistry principles and structures. Jakarta: Binarupa Aksara; 1999.

7. Syukri S. The basic chemistry. Volume II. Bandung: Institut Teknologi Bandung; 1999.

8. Cairns D. Essentials of pharmaceutical chemistry. $2^{\text {nd }}$ edition London: The Royal Pharmaceutical Society of Great Britain; 2003.

9. Hill JW, Petrucci RH. General chemistry an integrated approach. $3^{\text {rd }}$ Edition. New Jersey: Prentice-Hall; 2002.

10. Atkins P, Paula JD, Keeler J. Physical chemistry thermodynamic and kinetics. London. Oxford Press; 2006.

11. Sabaghi V, Davar F, Ferestheh Z. ZnS nanoparticles prepared via simple reflux and hydrothermal method: optical and photocatalitic properties. Ceramics Int 2018;44:7545-56.

12. Kesuma D, Santosa H. Synthesis of 2,4-dichlorobenzoyltiourea from 2,4-dichlorobenzylchloride and thiourea as a candidate for a central nervous system depressant drug through the reflux process. Indones Chem Eng Nat Sem Proc 2009;1:1-7.

13. Walpole RE. Introduction to statistics. eighth edition. London: Pearson Prentice Hall; 2007.

14. Astuti IA. GVT-0 synthesis reaction kinetics (observation of the rate of GVT-0 formation). Surakatra: Faculty of the Pharmacy Muhammadiyah University of Surakarta; 2011. 